\title{
Correlation of Hemoglobin A1c with Red Cell Width Distribution and Other Parameters of Red Blood Cells in Type II Diabetes Mellitus
}

\author{
Abdul Rabb Bhutto ${ }^{1}$, Amanullah Abbasi ${ }^{2}$, Ali Hassan Abro ${ }^{3}$ \\ 1. Internal Medicine, Al-Tibri Medical College \& Hospital Isra University Karachi Campus, Karachi, PAK 2. Internal \\ Medicine, Dow University of Health Sciences, Karachi, PAK 3. Internal Medicine, Southend University Hospital, \\ Southend, GBR
}

Corresponding author: Abdul Rabb Bhutto, drbhuttoarabb@yahoo.com

\section{Abstract}

\section{Objective}

To determine the correlation of glycated hemoglobin (HbA1c) with red cell width (RDW) and other analytic parameters of red blood cells (RBCs) in type II diabetic patients.

\section{Design}

Cross-sectional analytical study.

\section{Place and duration of the study}

Al-Tibri Medical College and Hospital Karachi; from July 2017 to January 2018.

\section{Patients and methods}

This cross-sectional study was conducted on diagnosed type II diabetic patients visiting the outpatient department of medicine at Al-Tibri Medical College Hospital from July 2017 to January 2018. Diabetes mellitus was diagnosed according to American Diabetes Association (ADA) guidelines. After taking consent and conducting a clinical assessment (include history and physical examination), laboratory tests, such as fasting blood glucose, random blood glucose, complete blood count ( $\mathrm{CBC}$ ), and $\mathrm{HbA1c}$, were collected on proforma.

\section{Results}

A total of 119 patients were eligible for the study with a mean age of $48.63 \pm 12.462$ (range 24-76) years; among those, males were $74(62.2 \%)$ and females were 45 (37.8\%). The mean duration of diabetes mellitus (DM) was $6.735 \pm 3.759$ (range 1-20) years. The mean hemoglobin of patients was $11.59 \pm 1.315 \mathrm{gm} / \mathrm{dl}$. The

Received 08/19/2019

Review began 08/23/2019 Review ended 08/29/2019 Published 08/30/2019

() Copyright 2019

Bhutto et al. This is an open access article distributed under the terms of the Creative Commons Attribution License CC-BY 3.0., which permits unrestricted use, distribution, and reproduction in any medium, provided the original author and source are credited. mean corpuscular volume (MCV) was $76.65 \pm 11.121 \mathrm{fl}$ and the mean RDW was found to be $18.287 \pm 4.352$, with the highest value of 30.20 . The mean $\mathrm{MCH}$ was $30.223 \pm 23.873 \mathrm{pg}$, with the highest value of $38.4 \mathrm{pg}$. The mean cell hemoglobin concentration (MCHC) was $28.214 \pm 4.7498 \mathrm{mg} / \mathrm{dl}$.

The HbA1c of the study population was found to be moderately uncontrolled and the mean HbA1c was $8.278 \pm 5.015 \%$, with the highest value of $16.2 \%$. The mean fasting blood sugar was $158 \pm 39.50 \mathrm{mg} / \mathrm{dl}$ while the mean random blood sugar was $236 \pm 57.390 \mathrm{mg} / \mathrm{dl}$.

The correlation of HbA1c with RDW turned out to be significant statistically (p-0.035) while other RBCs and/or hematological parameters, such as MCV, hemoglobin, and platelets, revealed no significant correlation.

\section{Conclusion}

The study highlighted that RDW has a significant correlation with HbA1c and is an inexpensive and freely available test so it may be used as a marker of glycemic status.

Categories: Endocrinology/Diabetes/Metabolism, Internal Medicine Keywords: rdw, hba1c, diabetes mellitus

\section{Introduction}

Globally, it is estimated that there are 382-million people living with diabetes, and the International Diabetes Federation has projected that 592-million people will have diabetes by 2035 [1]. The rising incidence and chronic nature lead to an increased risk of a complex complication profile of macrovascular 
and microvascular complications. Hence, following a diagnosis of diabetes, management, regular follow-up with an assessment for complications, and blood sugar monitoring always remain a big challenge for any health care provider, especially in low socioeconomic countries. The cost-effectiveness of those measures or tools for the assessment of complications status and blood sugar monitoring is highly desirable and encouraged. In this regard, recently, glycated hemoglobin (HbA1c) was used as a tool for glycemic control but since 2010, it is now accepted for the diagnosis of diabetes too [2]. The HbA1c concentration depends on the plasma glucose concentration and the duration of hyperglycemia. HbA1c concentration is measured as an index of glycemic control for a period over eight to 12 weeks.

Besides the glycosylation of hemoglobin, hyperglycemia has several other effects on red blood cells (RBCs) as well as changes in the mechanical properties of RBCs, reduced deformability, increased adhesion, and increased osmotic fragility, consequently leading to changes in erythrocyte structure and hemodynamic characteristics [3-4].

In recent years, the diagnostic and prognostic value of a parameter of RBCs, red cell distribution width (RDW), has been studied in various diseases like cardiovascular mortality [5] and peripheral artery disease [6]. RDW is a measure of variability in the size of RBCs and is a component of routine complete blood counts (CBCs). Traditionally, it is used together with the mean corpuscular volume (MCV) in clinical practice to differentiate between the causes of anemia [7].

Uncontrolled diabetes leading to the consistent elevation of $\mathrm{HbA1c}$ may induce functional and structural changes in the hemoglobin molecule and cytoplasmic environment within each red blood cell. Consequently, the RDW and other RBC parameters may be altered. As the microvascular complications of diabetes mellitus are well-proven and linked to increased HbA1c, alteration in RDW might have a role in the diagnosis and monitoring of glycemic status as well as complication assessment in diabetic patients. The aim of this study was to assess the correlation between HbA1c and RDW, as it is more cost-effective, routinely a component of $\mathrm{CBC}$.

\section{Materials And Methods}

\section{Patients and methods}

This cross-sectional analytical study was conducted on diagnosed type II diabetic patients visiting the outpatient department of medicine at Al-Tibri Medical College Hospital from July 2017 to January 2018. All patients provided written consent for data collection, which was approved by our institutional ethical committee. Diabetes mellitus was diagnosed according to American Diabetic Association (ADA) guidelines: $\mathrm{HbA} 1 \mathrm{c} \geqslant 6.5 \%$ or fasting blood glucose $(\mathrm{FBG}) \geqslant 126 \mathrm{mg} / \mathrm{dl}$ or two-hour plasma glucose $\geqslant 200 \mathrm{mg} / \mathrm{dl} \mathrm{during}$ an oral glucose tolerance test (OGTT).

Patients were excluded from the study if they had a history of hemoglobinopathies, anemia of any cause, chronic illnesses like chronic liver disease, chronic renal failure, rheumatologic disorders, and acute or chronic infections like malaria, tuberculosis, or malignancy. After taking consent, all the subjects underwent a detailed history, thorough physical examination, and routine relevant laboratory investigations for the implementation of inclusion and exclusion criteria.

The hematology analyzer - Nihon-Kohden Celltac-a (Tokyo, Japan) was used for blood parameters measurement while HbA1c was analyzed by the hemoglobin analyzer - GP Getein 1100 ( Getein Biotech, Inc., China)

Fasting blood glucose, random blood glucose, $\mathrm{CBC}$, and $\mathrm{HbA1c}$ were collected on proforma.

\section{Statistical analysis}

Data were analyzed by using SPSS 23 (Statistical Package for Scientific Studies; IBM Corp., Armonk, NY, US) for Windows. Data were described as mean and standard deviation (SD). Correlation between different variables was done using the Pearson moment correlation equation for a linear relation in normally distributed variables. A p-value of less than or equal to 0.05 was considered statistically significant.

\section{Results}

A total of 119 patients was found eligible for the study, with a mean age of $48.63 \pm 12.462$ (range 24-76) years, and out of those 119 patients, males were 74 (62.2\%) and females were 45 (37.8\%). On the basis of ethnicity, 54 (45.4\%) were Sindhi followed by Balochi 28 23.55), Pakhtoon 24 (202\%), Urdu 11 (9.2\%), and Punjabi 02 (1.7\%). According to marital status, the majority of the study population (92.4\%) was married. As per the educational status of the study population, 32 (26.9\%) subjects were either illiterate or only had incomplete Deeni/Madarsa education, 21 (17.6\%) had a primary level of education, 26 (21.8\%) had passed middle school, 27 (22.7\%) had completed matriculation, 12 (10.1\%) had finished intermediate school while only one (0.8\%) subject had graduated. The baseline demographics of the study subjects are shown in Table 1 . 


\section{Cureus}

\begin{tabular}{|c|c|c|}
\hline Variable & Frequency & Percentage \\
\hline \multicolumn{3}{|l|}{ Gender } \\
\hline Male & 74 & 62.2 \\
\hline Female & 45 & 37.8 \\
\hline \multicolumn{3}{|l|}{ Age (years) } \\
\hline Less than or equal 40 & 36 & 30.3 \\
\hline More than 40 & 83 & 69.7 \\
\hline \multicolumn{3}{|l|}{ Marital Status } \\
\hline Single & 09 & 7.6 \\
\hline Married & 110 & 92.4 \\
\hline \multicolumn{3}{|l|}{ Educational status } \\
\hline Deeni/Madarsa & 32 & 26.9 \\
\hline Primary & 21 & 17.6 \\
\hline Middle & 26 & 21.8 \\
\hline Matric & 27 & 22.7 \\
\hline Intermediate & 12 & 10.1 \\
\hline Graduate & 01 & 0.8 \\
\hline \multicolumn{3}{|l|}{ Language } \\
\hline Balochi & 28 & 23.5 \\
\hline Pakhtoon & 24 & 20.2 \\
\hline Punjabi & 02 & 1.7 \\
\hline Sindhi & 54 & 45.4 \\
\hline Urdu & 11 & 9.2 \\
\hline Total & 119 & 100 \\
\hline
\end{tabular}

\section{TABLE 1: Baseline demographics of study population ( $n-119)$}

The mean duration of DM was $6.735 \pm 3.759$ (range 1-20) years. The mean hemoglobin of patients was $11.59 \pm 1.315 \mathrm{gm} / \mathrm{dl}$. MCV was $76.65 \pm 11.121 \mathrm{fl}$ and mean RDW was found to be $18.287 \pm 4.352$, with the highest value of 30.20 . MCH was $30.223 \pm 23.873 \mathrm{pg}$, with the highest value of $38.4 \mathrm{pg}$. MCHC was $28.214 \pm 4.7498$ $\mathrm{mg} / \mathrm{dl}$. The HbA1c of the study population was found moderately uncontrolled and the mean HbA1c was $8.278 \pm 5.015 \%$, with the highest value of $16.2 \%$. The mean fasting blood sugar was $158 \pm 39.50 \mathrm{mg} / \mathrm{dl}$ while the mean random blood sugar was $236 \pm 57.390 \mathrm{mg} / \mathrm{dl}$.

The correlation of HbA1c with RDW turned out to be significant statistically (p-0.035) while other RBCs and/or hematological parameters like MCV, hemoglobin, and platelets revealed no significant correlation, as shown in Table 2. 


\section{Cureus}

\begin{tabular}{|l|l|l|}
\hline Parameter & Correlation & P-value \\
\hline Hemoglobin & 0.098 & 0.290 \\
\hline MCV & -0.127 & 0.167 \\
\hline MCH & -0.109 & 0.238 \\
MCHC & 0.051 & 0.583 \\
\hline RDW & 0.193 & $0.035^{*}$ \\
\hline FBS & 0.324 & $<0.0001^{\star}$ \\
\hline RBS & 0.388 & $<0.0001^{\star}$ \\
WBC & -0.025 & 0.869 \\
\hline Platelets & 0.108 & 0.244 \\
\hline
\end{tabular}

TABLE 2: Correlation of HbA1c with different hematological parameters $(n=119)$

MCV: Mean corpuscular volume; MCH: Mean corpuscular hemoglobin; MCHC: Mean corpuscular hemoglobin concentration; RDW: Red blood cell distribution width; FBS: Fasting blood sugar; RBS: Random blood sugar; WBC: White blood cells

\section{Discussion}

Diabetes mellitus is a metabolic disease secondary to either the deficiency or decreased responsiveness of tissues to insulin and is associated with derangements in the metabolism of carbohydrates, lipids, and proteins. Hence, insulin is a very important hormone in metabolic homeostasis. Persistent hyperglycemia resulting from insulin deficiency leads to the devastating and life-threatening complications of diabetes. Keeping this fact in mind, frequent monitoring of blood sugar is a key step in the management of diabetes. Traditionally, fasting and random or postprandial blood sugar have been used in glycemic monitoring. In recent years, $\mathrm{HbA1c}$ has been added as a tool to diagnose or monitor diabetes as well as play a role in predicting the complications, mortality, and morbidity of diabetes mellitus.

Persistently elevated plasma glucose is nonenzymatically glycated to hemoglobin A to form HbA1c, hence, the concentration of $\mathrm{HbA1c}$ depends on the level and duration of glucose in the plasma that is measured clinically as an index of diabetic control for a period over eight to 12 weeks.

Moreover, like HbA1c, RDW is also one of the parameters of RBCs, but it is reported along with a simple routine laboratory investigation of the $\mathrm{CBC}$ without any extra cost and can be defined as a marker of the variation in cell volume within the red cell population that is reported as an index of heterogeneity in the size of circulating erythrocytes [8]. RDW has been extensively studied in various studies on the etiology and diagnosis of anemia [9]. More recently, its diagnostic and prognostic role has been discovered in various diseases and their adverse outcomes have been associated with high RDW, such as increased mortality [10], bad prognostic marker in heart failure or ischemic heart disease patients [11-12], and a higher incidence of atrial fibrillation and heart failure [13-14].

In our study, we found a statistically significant correlation of RDW with HbA1c ( $r=0.193, p$ 0.035), and the same observations were evidenced by Suryavanshi et al. in their study $(r=-0.235, p=0.001)$ [15] while Salimon et al. found in their study that males have shown a significant correlation comparatively more than females ( $r=0.400$ vs $r=0.04$ ) [16]. Another study by Sherif et al. has also shown a positive correlation between RDW

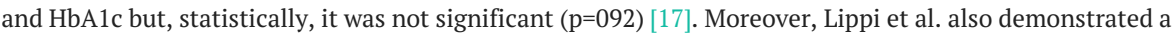
significant correlation of HbA1c and RDW in their study even after adjustment for age and gender [18].

While other parameters of RBCs like MCV, MCH, and MCHC have shown no significant correlation with $\mathrm{HbA1c}$. There is diversity in the results of previous studies regarding the correlation of these parameters and $\mathrm{HbA1c}$; a study by Hardikar et al. on non-diabetic subjects observed an inverse correlation between HbA1c and MCV ( $r=-0.22, p<0.05)$, MCH $(r=-0.30, p<0.05)$, and MCHC $(r=-0.32, p<0.05)[19]$ while another study by Koga et al. found HbA1c was inversely associated with MCV $(r=-0.368, p<0.0001)$ and MCH $(r=-0.320, p<0.0001)$ in premenopausal women but postmenopausal women have shown no such relation between HbA1c and MCV $(r=-0.019, \mathrm{p}=0.771)$ and $\mathrm{MCH}(\mathrm{r}=-0.104, \mathrm{p}=0.107)$ [20].

There were a few limitations to our study. First, this study was a single-center-based study with a limited sample so could not be a representation of the whole population of the country; second, the study was conducted based on duration, so the sample size was not calculated. 


\section{Conclusions}

As it is a well-known fact that diabetes mellitus is a life-long metabolic disease, patients with DM keep asking for cost-effective and easily available means of monitoring their glycemic status. In that context, our current study highlighted that RDW has a significant correlation with HbA1c and is an inexpensive and freely available test. Therefore, it may be used as a marker of glycemic status. However, further studies on a larger scale are required to detect this relation and its glycemic monitoring role in diabetic patients.

\section{Additional Information \\ Disclosures}

Human subjects: Consent was obtained by all participants in this study. Institutional Research Ethical Committee issued approval ATMC/IREC/2017/0021. Approved. Animal subjects: All authors have confirmed that this study did not involve animal subjects or tissue. Conflicts of interest: In compliance with the ICMJE uniform disclosure form, all authors declare the following: Payment/services info: All authors have declared that no financial support was received from any organization for the submitted work. Financial relationships: All authors have declared that they have no financial relationships at present or within the previous three years with any organizations that might have an interest in the submitted work. Other relationships: All authors have declared that there are no other relationships or activities that could appear to have influenced the submitted work.

\section{References}

1. Guariguata L, Whiting D, Hambleton I, Beagley J, Linnenkamp U, Shaw JE: Global estimates of diabetes prevalence for 2013 and projections for 2035. Diabetes Res Clin Pract. 2013, 103-137. 10.1016/j.diabres.2013.11.002

2. Nathan DM: International Expert Committee report on the role of the A1C assay in the diagnosis of diabetes. Diabetes Care. 2009, 32:1327-1334. 10.2337/dc09-9033

3. Symeonidis A, Athanassiou G, Psiroyannis A, Kyriazopoulou V, Kapatais-Zoumbos K, Missirlis Y, Zoumbos $\mathrm{N}$ : Impairment of erythrocyte viscoelasticity is correlated with levels of glycosylated haemoglobin in diabetic patients. Clin Lab Haematol. 2001, 23:103-109. 10.1046/j.1365-2257.2001.00366.x

4. Livshits L, Srulevich A, Raz I, Cahn A, Barshtein G, Yedgar S, Eldor R: Effect of short-term hyperglycemia on protein kinase C alpha activation in human erythrocytes. Rev Diabet Stud. 2012, 9:94-103. 10.1900/rds.2012.9.94

5. Al-Kindi SG, Refaat M, Jayyousi A, Asaad N, Al Suwaidi J, Abi Khalil C: Red cell distribution width is associated with all-cause and cardiovascular mortality in patients with diabetes. Biomed Res Int. 2017, 2017:1-7. 10.1155/2017/5843702

6. Enes D, Sevsen K, Egemen C, Mehmet O: Is there a real correlation between red cell distribution width and peripheral arterial disease?. J Med Biochem. 2017, 36:309-313. 10.1515/jomb-2017-0028

7. Montagnana M, Cervellin G, Meschi T, Lippi G: The role of red blood cell distribution width in cardiovascular and thrombotic disorders. Clin Chem Lab Med. 2011, 50:635-641. 10.1515/cclm.2011.831

8. Yaman H, Celik T, Akgul EO, Cayci T, Kurt Y: Red cell distribution width and acute coronary syndromes. Int J Cardiol. 2010, 145:353. 10.1016/j.ijcard.2009.11.010

9. Evans TC, Jehle D: The red blood cell distribution width. J Emerg Med. 1991, 9:71-74. 10.1016/07364679(91)90592-4

10. Perlstein TS, Weuve J, Pfeffer MA, Beckman JA: Red blood cell distribution width and mortality risk in a community-based prospective cohort. Arch Intern Med. 2009, 169:588-594. 10.1001/archinternmed.2009.55

11. Felker GM, Allen LA, Pocock SI, et al.: Red cell distribution width as a novel prognostic marker in heart failure: data from the CHARM program and the Duke Databank. J Am Coll Cardiol. 2007, 50:40-47. 10.1016/j.jacc.2007.02.067

12. Tonelli M, Sacks F, Arnold M, Moye L, Davis B, Pfeffer M: for the CARE Trial Investigators. Relation between red blood cell distribution width and cardiovascular event rate in people with coronary disease. Circulation. 2008, 117:163-168.

13. Borne Y, Smith JG, Melander O, Hedblad B, Engstrom G: Red cell distribution width and risk for first hospitalization due to heart failure: a population-based cohort study. Eur J Heart Fail. 2011, 13:1355-1361. 10.1093/eurjhf/hfr127

14. Eryd SA, Borné Y, Melander O, Persson M, Smith JG, Hedblad B, Engström G: Red blood cell distribution width is associated with incidence of atrial fibrillation. J Intern Med. 2014, 275:84-92. 10.1111/joim.12143

15. Suryavanshi C, Manjula SD, Bekur R, Rao RK: Association of increased levels of glycated hemoglobin with variations in red blood cell parameters in diabetes mellitus. Int J Adv Res (Indore). 2015, 3:31-37.

16. Salimon AH, Patil HA: Correlation of red blood cell distribution width (RDW) and hemoglobin A1C (HbA1C) levels in diabetic individuals. Int J Innov Res Sci Eng Technol. 2017, 6:8227-8239.

17. Sherif H, Ramadan N, Radwan M, Hamdy E, Reda R: Red cell distribution width as a marker of inflammation in type 2 diabetes mellitus. Life Sci J. 2013, 10:1501-1507.

18. Lippi G, Targher G, Salvagno GL, Guidi GC: Increased red blood cell distribution width (RDW) is associated with higher glycosylated hemoglobin (HbA1C) in the elderly. Clin Lab. 2014, 60:2095-2098. 10.7754/clin.lab.2014.140621

19. Hardikar P, Joshi S, Bhat D, et al.: Spuriously high prevalence of prediabetes diagnosed by HbA1c in young Indians partly explained by hematological factors and iron deficiency anemia. Diabetes Care. 2012, 35:797802. 10.2337/dc11-1321

20. Koga M, Morita S, Saito H, Mukai M, Kasayama S: Association of erythrocyte indices with glycated haemoglobin in pre-menopausal women. Diabet Med. 2007, 24:843-847. 10.1111/j.1464-5491.2007.02161.x 